\title{
Knowledge, Attitudes and Practices of Mothers of Under-Five Regarding Prevention of Malaria in Children: Evidence from ogun State, Nigeria
}

\author{
Kio Janet $\mathrm{O}^{1}$; Agbede Catherine $\mathrm{O}^{2}$; Olayinka Folake $\mathrm{E}^{3}$; Omeonu Precious $\mathrm{E}^{2}$ \\ and Dire-Arimoyo Yewande ${ }^{1}$ \\ ${ }^{I}$ Department of Nursing Science, Babcock University \\ ${ }^{2}$ Department of Public Health, Babcock University, Nigeria \\ ${ }^{3}$ Department of Medicine, Obafemi Awolowo University, Nigeria
}

\begin{abstract}
Malaria is an infectious disease and a serious health issue that needs urgent attention especially in children less than 5 years. The study aims at assessing the knowledge, attitude and practices of mothers regarding the prevention of malaria in children between 0-5 years. Convenience sampling method was used to select 160 mothers that attend child survival clinic and children outpatient clinic in olabisi onabanjo university teaching hospital (OOUTH), sagamu, Ogun State. Questionnaire was used to collect data from the respondents, and the data was analysed using statistic package for social sciences (SPSS, version 17). Findings from the study showed that $55 \%$ of the respondents had a good knowledge about malaria, $78 \%$ of the respondents had a positive attitude regarding malaria prevention, $37 \%$ of the respondents practiced malaria prevention. The factors which influenced respondents' practice of prevention were the age of mothers, their income level and the frequency of malaria episode. Despite the fair overall knowledge and good attitudes, practices towards malaria prevention were poor. Therefore interventions aimed at social and behaviour change should primarily target the gaps in practices highlighted by the study.
\end{abstract}

Keywords - Attitude, Knowledge, Malaria, Nigeria, Preventive practices, Under-five.

\section{INTRODUCTION}

Malaria continues to be a leading cause of morbidity and mortality in many tropical regions of the world even though it is both preventable and treatable, and effective preventive and curative tools have been developed. Despite global efforts to eradicate the disease it remained a great challenge to health system for countries in the developing world. It is also a public-health problem and the principal cause of childhood mortality [1]. It is a vector-borne infectious disease caused by plasmodium. Malaria is widespread in tropical and subtropical regions in a broad band around the equator. It is prevalent in tropical and subtropical regions because rainfall, warm temperatures, and stagnant waters provide habitats suitable for mosquito to breed.

Five species of plasmodium can infect and be transmitted by humans, however, majority of deaths from malaria are caused by plasmodium falciparum while plasmodium vivax, plasmodium ovale, and plasmodium malarie causes a generally milder form of malaria that is rarely fatal. The zoonotic species, plasmodium knowlesi is prevalent in Southeast Asia; it causes malaria in macaques, but can also cause severe infections in humans. The disease causes symptoms that typically begin 8-25days following the infection, symptoms may occur later in those who have taken anti malaria medications as prevention. The classic symptom of malaria is paroxysm - cyclical occurrences of sudden coldness followed by rigor and then fever [2]. Severe malaria has varying patterns and the relative contributions to individual symptoms to mortality differ with endemicity, geographic locations and access to health services [3].

Malaria accounts for $20 \%$ of under-five mortality and $25 \%$ of childhood mortality [4]. According to Erhun, Agbani and Adesanya [5], over 90\% of malaria cases occur in Sub-Saharan Africa, where a child under the age of 5 years dies from this illness every 30 seconds. In Nigeria, the burden of malaria is well documented and has been shown to be a big contributor to the economic burden of disease in communities where it is endemic and is responsible for annual economic loss to the tune of 132 billion Naira [6]. It is estimated that out of 300,000 deaths occurring each year, $60 \%$ of outpatient visits and $30 \%$ hospitalizations are all caused by malaria [7]. No doubt Nigeria is a malaria-endemic area and malaria is the principal cause of childhood mortality.

According to Wilson [3], global malaria deaths peaked at 1.82 million in 2004 and have fallen steadily since then, dropping by $32 \%$ to 1.24 million in 2010 ( 714,000 children aged less than 5 years, 524,000 individuals aged less than or equal to 5years). However, the number of deaths in individuals aged less than or 
equal to 5 years in 2010 exceeded WHO estimates by 433,000. The situation has remained consistent ever since, this is why investigation on how to mitigate malaria spread among under-five is pertinent and of policy relevance. Uzochukwu et al. [7] stated that malaria is common among pregnant women and children under 5 years of age due to their low levels of immunity. This is why these categories of the population were the primary focus of the Roll Back Malaria (RBM) program. , RBM aims at maintaining an overall vision of a malaria-freeworld. The goals and targets for malaria control was to reduce global malaria deaths to near zero by 2015 , reducing global malaria cases by $75 \%$ from what it was in 2000 by end of 2015 and eliminate malaria by end 2015 in 10 new countries [8]. This goal is yet to be achieved.

The increase in the prevalence of malaria is Nigeria is due to both behavioural and non-behavioural factors [9]. The behavioural factors relates to some cultural practices, which promote mosquito breeding and mosquitoes' access to the people as well as the failure of 'at risk' population to use technologies proven to be effective for the treatment, control and prevention of malaria promptly and adequately. The non-behavioural factors include geographical or ecological peculiarities, the availability of mosquitoes and the presence of plasmodia. Thorough understanding of both behavioural and non-behavioural factors is very important for the design of appropriate interventions for tackling malaria [10]. Creating awareness and improving the understanding of the transmission of malaria has been found to greatly contribute to ameliorating malaria menace and facilitate the sustainability of malaria elimination programmes [8]. It is against this backdrop that this paper examined the knowledge, attitudes and practices of mothers regarding the prevention of malaria in children between 0-5 years.

\section{METHODOLOGY}

This study was carried out in Olabisi Onabanjo University Teaching Hospital (OOUTH), Sagamu, Ogun State in Nigeria. OOUTH, established in 1983, is a tertiary health institution owned and managed by the State government. The study specifically targeted women with children below five (5) years old attending the child survival clinic and mothers who attended the children out-patient clinic in the Teaching Hospital. According to the register, 200 mothers (with under-five children) attended child survival clinic while 50 mothers attended children outpatient clinic between August and September 2015 (period of data collection). Thus, a total of 250 mothers was the population of the respondents.

Following Yamane [9], the sample size was calculated from a population of 250 women with underfive children in the study area (monitoring \&evaluation unit in Ibadan north east local government):

$$
\mathrm{n}=\mathrm{N} / 1+\left\{\mathrm{N}\left(\mathrm{e}^{2}\right)\right\}
$$

Where: $\mathrm{n}=$ minimum sample size, $\mathrm{N}=$ total number of population (which was 250 for this study) and e=level of precision $(\mathrm{e}=0.05)$ which is constant. Thus, the estimated minimum sample size was 154 respondents however, a total of 160 mothers were randomly sampled, through balloting, to take care of poor responses.

Data collection was done using structured questionnaire. Information gathered included demographic, respondents' knowledge, attitude and practices with respect to malaria prevention in their children. Furthermore, the questionnaire was validated and subjected to reliability test using the Cronbach's Alpha test. Result of the test showed that the average Cronbach's Alpha value for all the constructs in the instrument was 0.88 which clearly indicated that the instrument was reliable. Data collected were analyzed using the statistical package for social sciences (SPSS version 17.0). Both descriptive and inferential statistics were employed to present results for the study. The consent of all the participants were sought prior to data collection and ethical clearance was obtained from Olabisi Onabanjo University teaching Hospital in Ogun state.

The logit regression model was employed to examine the factors that influence malaria prevention practices. For the purpose of this study, any of the four common and selected practices was conceived to reflect the adoption of preventive practice. The four major prevention methods identified were environmental sanitation, use of mosquito nets, use of mosquito repellant or spray and use of anti-malaria drugs. The model is specified as follows:

$\operatorname{Ln}\left(\mathrm{P}_{\mathrm{i}} /\left(1-\mathrm{P}_{\mathrm{i}}\right)\right)=\beta_{0}+\beta_{1} \mathrm{X}_{1}+\ldots .+\beta_{14} \mathrm{X}_{14}+\mathrm{e}_{\mathrm{i}} \ldots \ldots$ Gujarati [12]

Where

The dependent variables are the natural $\log$ of the probability of adoption of a preventive practice $\left(\mathrm{P}_{\mathrm{i}}\right)$ divided by the probability of not adopting $\left(1-\mathrm{P}_{\mathrm{i}}\right), \beta_{\mathrm{o}}=$ the intercept, $\beta_{1 \ldots 14}=$ regression coefficients, $\mathrm{X}_{1 \ldots 14}$ independent variables, and ei $=$ error term..

The independent variables specified as factors affecting the adoption of preventive practice, and are defined below:

$\mathrm{X}_{1}=$ Age (years)

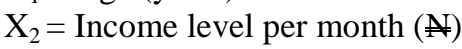

$\mathrm{X}_{3}=$ Educational level (years)

$\mathrm{X}_{4}=$ knowledge level

$\mathrm{X}_{5}=$ Attitude 
$\mathrm{X}_{6}=$ Frequencies of malaria attack per year

\section{RESULTS AND DISCUSSION}

The results of the data analysis for this study are presented in this section. Results of respondents' sociodemographic characteristics, knowledge, attitude and preventive practices with respect to malaria are presented here.

\subsection{Respondents' personal characteristics}

Respondents' personal attributes analyzed included age of mother and child, marital status, level of educational, occupation type, religion and frequency of malaria cases (how often their children have had malaria episode). Results, as presented in Table 1, showed that most of the respondents were between 20 and 30 years old (73\%) and mostly civil servants (36\%). By implication, most of these women, being young, are expected to be new to child bearing and nursing, however, further result showed that 51 percent of the women have had previous births. This shows the likely existence of early marriage and child bearing in the study area. Most of respondents had relatively good level of education with majority having secondary education and above (84\%). The nexus between education and health seeking behaviour has been detailed in previous studies $[6,13]$. Thus their level of education is expected to influence their search for knowledge, attitude and practices regarding prevention of malaria in their children. Since most of the women are civil servants, they may not necessarily depend on their husbands for household financial sustenance and immediate care for their children, especially during emergencies. As at the time of data collection, some 54 percent of the respondents had children below 3 years of age.

Table 1: distribution of respondents by their personal characteristics

\begin{tabular}{lll}
\hline Variables & Frequency & Percentage \% \\
Age: & 116 & 72.5 \\
$20-30$ & 31 & 19.4 \\
$31-40$ & 13 & 8.1 \\
$>40$ & & \\
Occupation: & 57 & 35.6 \\
Civil servants & 52 & 32.5 \\
Traders & 51 & 31.9 \\
Student s & & \\
Religion: & 201 & 78.1 \\
Christianity & 169 & 21.9 \\
Islam & & \\
Educational level: & 24 & 15.4 \\
Primary & 96 & 59.6 \\
Secondary & 40 & 24.8 \\
Tertiary & 145 & 90.6 \\
Marital status: married & & \\
Child's age in years: & 40 & 25.0 \\
1 & 47 & 29.4 \\
2 & 44 & 27.5 \\
3 & 29 & 18.1 \\
4 & 82 & 51.2 \\
Had previous births: yes & & \\
Frequency of malaria cases with my under-five & & 53.8 \\
children: & 20 & \\
Seldom & 54 & \\
Moderate & 86 & \\
Very frequent & & \\
\hline
\end{tabular}

Source: computed from field survey data (2015)

\subsection{Respondents' knowledge of malaria infection and prevention}

Respondents' knowledge regarding malaria infection and prevention were assessed and results presented in Table 2. Levels of knowledge regarding mode of infection and transmission, symptoms, prevention of malaria were measured following the Ashur [14] measurement scale. According to Ashur, proportion or score less than 40 percent correct response should be taken as indicator of low level of knowledge, 40 - 59 percent is considered average and $60-80$ per cent is considered high, while over 80 per cent is regarded as very high level of knowledge. 
Table 2: Distribution of respondents by knowledge of malaria infection and prevention

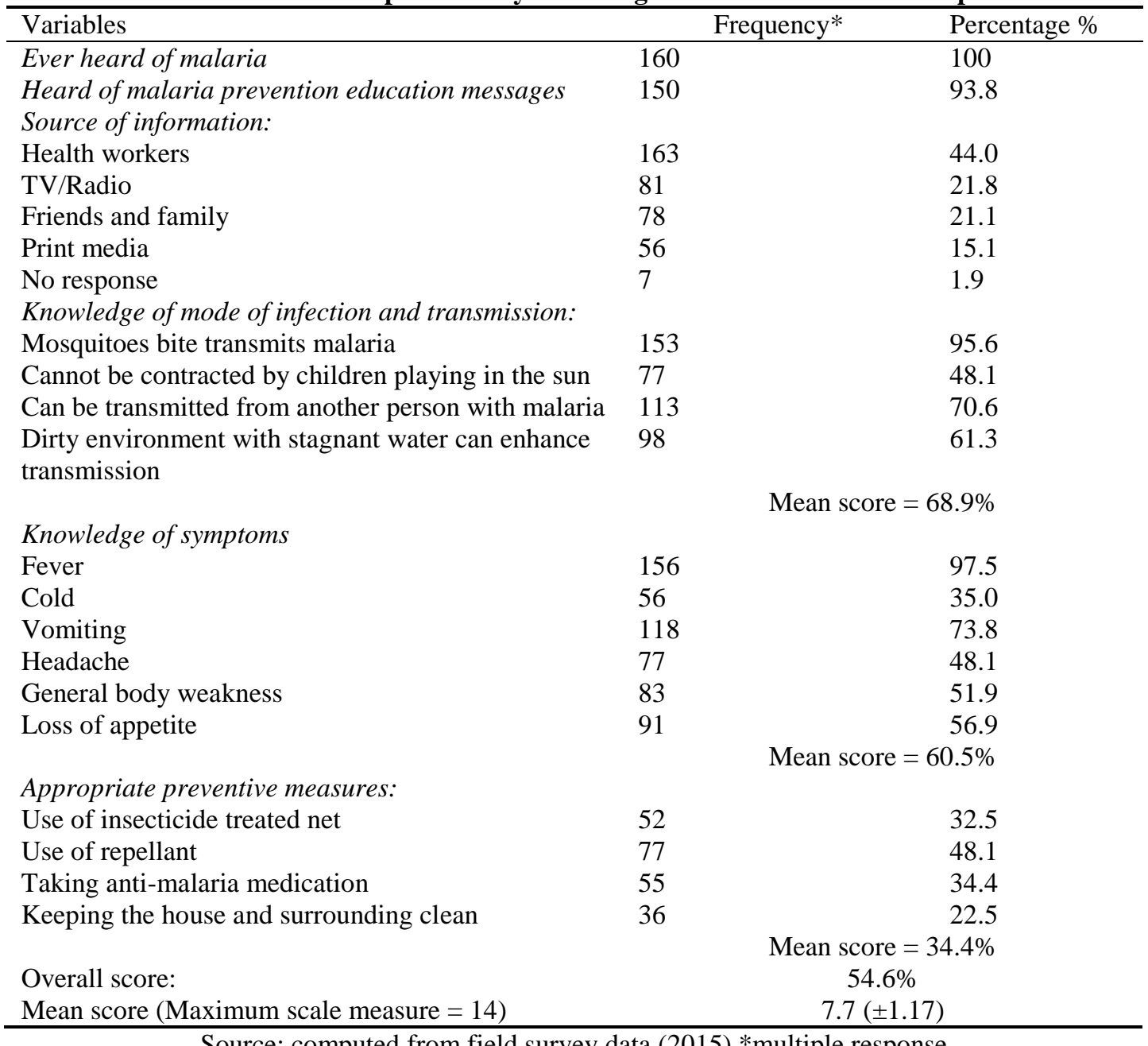

Source: computed from field survey data $(2015) *$ multiple response

Results in Table 2 showed all the women have heard of malaria and almost all of them have heard of malaria prevention education message (94\%) especially from the health workers. The result showed that the women had average knowledge level (mean score for correct response $=69 \%$ ) for knowledge about mode of infection and transmission, however, almost 40 percent of the respondents did not know that malaria can be transmitted more easily in a dirty environment with stagnant water and overgrown grasses. This will likely influence the kind of preventive measure adopted by these individuals. Further result showed that women had average knowledge level (mean score for correct response $=61 \%$ ) for knowledge about symptoms of malaria. Adequate knowledge of symptom will likely influence attitude and promptness to seeking treatment for children infected with malaria, thus preventing further spread to healthy ones. Respondents' level of knowledge regarding appropriate preventive measures to be taken to reduce malaria was low (mean score for correct response $=34 \%$ ). Only 23 percent of the women knew that keeping the environment clean can prevent malaria spread. This result corroborates earlier result on mode of infection. The use of mosquito repellant as preventive measure ranked highest among respondents (48\%). Similar results showing poor knowledge of Nigerian mothers regarding cause, symptoms and preventive measures for childhood diseases, despite the literacy level of these caregivers, have been reported by previous studies $[6,15,16]$. When all the knowledge statements were scored, with the right answer scoring 1 point and the wrong answer 0 point, an overall mean score of $7.7 \pm 1.17$ was obtained out of a maximum scale measure of 14 . This is just slightly above average score and inadequate to achieve appropriate healthcare practices. Studies have proved that improved knowledge of malaria and its source of transmission can promote preventive and personal protection practices amongst the affected community [17].

\subsection{Respondents' attitude regarding prevention of malaria in under-five children}

Result of respondents' attitude regarding prevention of malaria in their under-five children is presented in Table 3. The women were assessed for positive and negative attitudes. Generally, the respondents exhibited high 'positive' attitude towards prevention of malaria (78\%) and low 'negative' attitude (39\%). However, 67 percent 
of the respondents favoured self medication. When both positive and negative statements are scored with the right answer scoring 4 points and the wrong answer 1 point following the likert scale, an overall mean score for attitude was determined to be $21.6 \pm 5.8$ out of a maximum of 28 . This result showed that the women in the study area see malaria as a serious health challenge for their under-five. This is expected to translate to good malaria prevention practices.

Table 3: Respondents attitude regarding prevention of malaria in under-five children

\begin{tabular}{|c|c|c|}
\hline Attitudes statements & Frequency* & Percentage $\%$ \\
\hline \multicolumn{3}{|l|}{ Positive statements: } \\
\hline $\begin{array}{l}\text { Malaria prevention is highly important in children because it } \\
\text { is serious and life threatening }\end{array}$ & 145 & 90.6 \\
\hline $\begin{array}{l}\text { To prevent malaria me and my child must avoid mosquito } \\
\text { bite }\end{array}$ & 109 & 68.1 \\
\hline $\begin{array}{l}\text { Sleeping under mosquito net is one way to prevent getting } \\
\text { malaria }\end{array}$ & 125 & 78.1 \\
\hline $\begin{array}{l}\text { I might be at greater risk if my environment is overgrown } \\
\text { with bushes }\end{array}$ & 96 & 60.0 \\
\hline $\begin{array}{l}\text { It is dangerous when malaria medicine is not taken } \\
\text { completely }\end{array}$ & 131 & 81.9 \\
\hline \multirow{2}{*}{$\begin{array}{l}\text { I believe that I should go to the clinic every time I suspect my } \\
\text { child has malaria }\end{array}$} & 140 & 87.5 \\
\hline & \multicolumn{2}{|c|}{ Mean score $=77.7 \%$} \\
\hline \multicolumn{3}{|l|}{ Negative statement: } \\
\hline $\begin{array}{l}\text { I can easily and cheaply treat myself and my baby if we have } \\
\text { malaria }\end{array}$ & 107 & 66.9 \\
\hline $\begin{array}{l}\text { It is possible to recover from malaria without treatment so no } \\
\text { need for serious need incurring preventive costs }\end{array}$ & 24 & 15.0 \\
\hline $\begin{array}{l}\text { People who have malaria should be isolated to prevent its } \\
\text { spread }\end{array}$ & 32 & 20.0 \\
\hline $\begin{array}{l}\text { Only pregnant women and children are at risk of malaria so } \\
\text { they are the only ones that need serious protection }\end{array}$ & 88 & 55.0 \\
\hline & \multirow{2}{*}{\multicolumn{2}{|c|}{$\begin{array}{l}\text { Mean score }=39.2 \% \\
21.6( \pm 5.80)\end{array}$}} \\
\hline Overall Mean score (Maximum scale measure $=28$ ) & & \\
\hline
\end{tabular}

Source: computed from field survey data $(2015) *$ multiple response

\subsection{Respondents' major malaria prevention measures/practices used for children}

Respondents were further assessed based on the major prevention methods they use in reducing malaria attack on their children. The four major prevention methods identified were environmental sanitation, use of mosquito nets, use of mosquito repellant or spray and use of anti-malaria drugs. Results in Table 4 showed that for environmental sanitation, $87 \%$ perceived that the method was available but only $22 \%$ preferred this method for controlling malaria and only $30 \%$ were actually using it as at the time of the survey. For the use of mosquito nets, $58 \%$ perceived this method is available, 35\% preferred using it above other methods and only $33 \%$ were currently using mosquito nets to prevent malaria episode. For the use of mosquito repellants, $75 \%$ of respondents perceived that the method was available but only $25 \%$ preferred this method for controlling malaria and some $49 \%$ were currently using it as at the time of the survey. For the use of anti-malaria drug, $70 \%$ perceived this method is available, $42 \%$ preferred using anti-malaria drugs to control malaria in their children but only $36 \%$ were currently using it. Generally the least perceived method available for preventing malaria attack and spread was the use of mosquito nets. However, more of the women preferred using nets to environmental sanitation (which is the least preferred method) and mosquito repellants. This means that despite the government efforts with distributing treated nets to pregnant mothers and mothers of under-five, under the Rollback Malaria policy, many of the mothers still do not have access to these nets. The most adopted method for preventing malaria in the study area is the mosquito repellant despite the fact that it is not the most preferred or most available and the possible cost implication. This may be because the respondents believed in prevention via vector control. This also shows their poor knowledge that mosquitoes can be controlled more effectively and cheaply via environmental sanitation and use of insecticide impregnated nets. This results is consistent with the findings of Schultz et al. [18]; Tsuyuoka, Wagatsuma and Makunike [19]and Erhun, Agbani and Adesanya [5]. 
Table 4: Distribution of respondents' by major malaria prevention measures/practices used for children

\begin{tabular}{|l|c|c|c|c|c|}
\hline Practices & $\begin{array}{c}\text { Environmental } \\
\text { sanitation }\end{array}$ & $\begin{array}{c}\text { Use of } \\
\text { mosquito } \\
\text { nets }\end{array}$ & $\begin{array}{c}\text { Use of } \\
\text { mosquito } \\
\text { repellants }\end{array}$ & $\begin{array}{c}\text { Use of } \\
\text { anti- } \\
\text { malaria } \\
\text { drug }\end{array}$ & mean \\
\hline $\begin{array}{l}\text { Respondents' } \\
\text { perceiving method } \\
\text { as available }\end{array}$ & $139(86.8 \%)$ & $\begin{array}{c}93 \\
(58.1 \%)\end{array}$ & $\begin{array}{c}120 \\
(75.0 \%)\end{array}$ & $\begin{array}{c}112 \\
(70.0 \%)\end{array}$ & $72.5 \%$ \\
\hline $\begin{array}{l}\text { Respondents' } \\
\text { preferring method } \\
\text { of prevention }\end{array}$ & $35(21.9 \%)$ & $\begin{array}{c}56 \\
(35.0 \%)\end{array}$ & $40(25.0 \%)$ & $67(41.8 \%)$ & $30.9 \%$ \\
\hline $\begin{array}{l}\text { Respondents' } \\
\text { currently using } \\
\text { method of } \\
\text { prevention. }\end{array}$ & $48(30.0 \%)$ & $\begin{array}{c}53 \\
(33.1 \%)\end{array}$ & $78(48.8 \%)$ & $57(35.6 \%)$ & $36.8 \%$ \\
\hline
\end{tabular}

Source: Computer from field survey data (2015).

\subsection{Factors influencing malaria prevention practices}

The regression result as presented in Table 5 showed that out of all independent variables, the coefficient of the age of the mothers $(\mathrm{p}<0.1)$, income level $(\mathrm{p}<0.05)$ and frequency of malaria episode $(\mathrm{p}<$ $0.05)$ were significant with appropriate signs. This implies that mothers' income and frequency of malaria episode increases the probability of the respondents' using one or more preventive measure to control malaria. The coefficient for the age of the respondents $(\mathrm{p}<0.1)$ was significant with a negative sign showing an inverse relationship between age and the probability of the respondents taking preventive measure. This implies that older women show less interest in the prevention of malaria. This result is consistent with the findings of Babalola et al. [6]. It is not surprising that knowledge and attitude of the respondents did not significantly influence their prevention practices even though these variables were expected to influence prevention practices. Judging from earlier descriptive results, they have overall relatively good knowledge and positive attitude yet only $37 \%$ were currently using any prevention. This result is similar to the investigation of Batega [20] in Uganda on knowledge, attitude and practices related to malaria prevention and control which found out that despite high levels of knowledge and positive attitudes towards prevention of malaria, the practice of malaria preventive methods is generally low.

Table 5: Factors influencing malaria prevention practices

\begin{tabular}{|c|c|c|}
\hline Independent variables & Beta coefficient & t-ratio \\
\hline Constant & .353 & 2.957 \\
\hline Age of mother & $-0.091 *$ & 1.856 \\
\hline Educational level & 0.598 & 1.214 \\
\hline Income level & $0.067 * *$ & 2.220 \\
\hline $\begin{array}{l}\text { Knowledge level (score of } \\
\text { responses) }\end{array}$ & 1.045 & 1.064 \\
\hline $\begin{array}{l}\text { Attitude (score of } \\
\text { responses) }\end{array}$ & 0.101 & 1.003 \\
\hline $\begin{array}{l}\text { Frequency of malaria } \\
\text { episode }\end{array}$ & $0.394 * *$ & 2.297 \\
\hline
\end{tabular}

\section{CONCLUSION AND RECOMMENDATION}

The study aimed assessed the knowledge, attitudes and practices of mothers of under-five in relation to malaria prevention in Ogun state, Nigeria. In general, most of the respondents had fair knowledge about malaria transmission and symptom but poor knowledge regarding prevention and control. Despite the fair overall knowledge and good attitudes, practices towards malaria prevention were poor. Therefore interventions aimed at social and behaviour change should primarily target the gaps in practices highlighted by the study.

Based on the findings in this study, the following issues should be considered for improving preventive practices against malaria among mothers of under-five in the study area and in Nigeria in general: 
1. Special attention should be focused on improving respondents' knowledge about appropriate preventive measures for controlling malaria. Appropriate educational intervention that addresses the gap in knowledge as highlighted in the study, to corroborate the health information these women receive from the clinic is imperative.

2. While more efforts should be made to make the mosquito treated nets more available and cheaply accessible and even free to women attending clinics, healthcare programmes should incorporate women empowerment schemes so as to enhance their ability to meet cost of healthcare.

3. Community healthcare service providers should include in their services the counsel of communities on the importance of environmental sanitation

\section{REFERENCES}

[1] Akerele, A., Oyindamola, O., and Yusuf, Factors associated with the use of guideline in home management of malaria among children in southern part of Nigeria. Journal of malaria research and treatment, 2010. Retrieved May 2015 from http:/dx.doi.org/10.4061/2011/701320.

[2] Hay, S.I., Guerra, C.A., Gething, P.W., Patil, A.P., Tatem, A.J., Noor, A.M., A world malaria map: Journal of medical sciences, 31 (3), 2009, 461- 465.

[3] Wilson, M.L, Malaria rapid diagnostic tests. J. of clinical infectious diseases, 54 (11), 2013, 41- 56.

[4] Ekong, E.U and Angela, E., (2013). Malariometric Indices among Nigerian Children in a Rural Setting. Malaria research and treatment, 2013. Retrieved May 2015 from: http://hinari-gw.who.int/

[5] Erhun W.O, Agbani E. and Adesanya S.O (2005) Malaria Prevention: Knowledge, Attitude and Practice In A Southwestern Nigerian Community. African Journal of Biomedical Research, 8, 2005, 25 - 29. Available online at http://www.bioline.org.br/md

[6] Babalola, DA, Olarewaju M, Omeonu PE, Adefelu A O and Okeowo, R, Assessing the adoption of Roll Back Malaria Programme (RBMP) among women farmers in Ikorodu Local government area of Lagos state. Canadian Journal of Pure and Applied Science. 7 ( 2), 2013, 2375-2379

[7] Uzochukwu, B.S., Ezeoke, O.P., Emma-Ukaegbu, U., Onwujekwe, O.E., \& Sibeudu, F.T., Malaria treatment services in Nigeria. Nigerian medical journal, 51 (4), 2013, 114-119.

[8] WHO. (2012). Guidelines for the Treatment of Malaria, (Ed.2.). World Health Organization.

[9] Yamane, Taro, Elementary sampling theory. Englewood Cliffs, N.J. : Prentice-Hall, 1967

[10] Onwujekwe, O., Ojukwu, J., Shu, E., \& Uzochukwu, B, Inequities in evaluation of benefits of choice of drugs, and mode of payment for malaria treatment services provided by community health workers in Nigeria. American tropical journal, 77(9), 2007, 16-21.

[11] Korenromp, M.N., Williams, B., Gouws, E., Gilks, C. Ghys, P., Nahlen, B., Malaria attributable to the HIV-1 epidemic, sub-Saharan Africa. Emerging Infectious Diseases 11 (9), 2005, 1409-1410.

[12] Gujarati, D.N. (1998): Basic Econometrics. 2nd edition. New York, New York: McGraw-Hill.

[13] Omeonu PE; Babalola DA and Agbede OC, Qualitative Analysis of Adolescents' Sexual Behaviour in Ogun State, Nigeria: Implication for HIV/AIDS Policy. Journal of Biology, Agriculture and Healthcare, 4 (24), 2014, 162-166.

[14] Ashur, SS (1977). An evaluation plan for the development of updating of Nutrition Curriculum at Upper Elementary and Preparatory levels in Jordan. IVES/UNESCO International conference in Nutrition Education NE (Oxford), 207(2), 1977, 67-74

[15] Agu AP, and Nwojiji JO, Childhood malaria: Mothers' perception and treatment-seeking behaviour in a community in Ebonyi State, South East Nigeria. J Comm Med Prim Health Care 17, 2005, 45-50.

[16] Akande TM, Owoyemi A, and Owoyemi JO, Healthcare-seeking behaviour in Anyigba, north-central, Nigeria. Res J Med Science. 3, 2009, 47-51.

[17] Ahorlu, C.K., Koram, K.A., Arholu, C., De Savigny, D. and Weiss, M.G., Socio-cultural determinants of treatment delay for childhood Malaria in southern Ghana. Trop Med Int Health, 11(7), 2006, 46-53

[18] Schultz, L.J., Effling, M., Chitsulo, L., Steketee, R.W., Nyasulu, Y., Macheso, A., Nwanyanwu, O, A nationwide malaria knowledge, attitude and practices survey in Malawi: objectives and methodology. Trop. Med. and Parasit; 45, 1994, 54-56.

[19] Tsuyuoka, R, Wagatsuma, Y, Makunike B, The knowledge and practice on malaria among community members in Zimbabwe. Cent. Afr. J. Med.; 47(1), 2001, 14-7

[20] Batega, D., Accelerating progress in achieving the millennium development goal for children through community-based approaches. Journal of malaria research and treatment, 2009. Retrieved May 2015 from http://hinari-gw.who.int/ 